\title{
Greater Moncton Poll
}

As part of Moncton's second immigration strategy, city leaders have turned to the public to gauge their understanding of immigration and solicit their feedback on plans for the city's future. Below is the public opinion poll that was disseminated during the consultation phase of the immigration strategy. The public opinion poll is illustrative of the kinds of myths about immigration that need clarification in addition to facts about immigration that need to be boldly stated. Using the Measuring Up worksheet and adapting this survey, you too can take the pulse of immigration in your city.

1] True or False: The number of people born in Canada and working in New Brunswick has been increasing since 2008?

$>$ True

$>$ False

$>$ Unsure

2] Between 2011 and 2016, immigrants accounted for what percentage of Greater Moncton's population growth?

$>62 \%$

$>51 \%$

$>12 \%$

$>43 \%$

3] True or False: More than 100 Greater Moncton businesses are owned by immigrants.

$>$ True

$>$ False

$>$ Unsure

4] True or false: The immigrant workforce has a higher unemployment rate than the general population.

$>$ True

$>$ False

$>$ Unsure

5] How many international students are in our postsecondary institutions in the region?

$>$ More than 1,000

$>$ Less than 1,000

$>$ Unsure

6] In recent years, Greater Moncton's immigration rate has more than:

$>$ Doubled

$>$ Tripled

$>$ Unsure
7] How many workers in Westmorland and Albert counties are over the age of 55 ?

$>5,000$

$>10,000$

$>20,000$

8] In Greater Moncton, which industries are threatened by the decline in the labor force?

$>$ Finance and insurance

$>$ Manufacturing

$>$ Transportation and warehousing

$>$ Information technology

$>$ Health care

$>$ Tourism

9] How many positions have been filled in Greater Moncton through job fairs for international students and newcomers?

$>$ Less than 100

$>123$

$>210$

$>$ More than 250

10] True or false: In Greater Moncton, immigrants have a higher rate of self-employment.

$>$ True

$>$ False

$>$ Unsure

11 In 2018, the international student enrollment at the Université de Moncton and Mount Allison University accounted for what percentage of all international university students in the province?

$>38 \%$

$>12 \%$

$>44 \%$

12] How many ethnocultural associations are there in Greater Moncton?

$>$ Less than 10

$>15$

$>$ More than 20 